\title{
Response-independent outcomes impact response rates and judgments of control differentially depending on rate of response-dependent outcomes
}

\author{
Phil Reed ${ }^{1}$
}

Published online: 28 May 2015

(C) Psychonomic Society, Inc. 2015

\begin{abstract}
Two experiments examined the impact of responseindependent outcome delivery on human rates of response and judgments of control in an instrumental conditioning task. In Experiment 1, when participants responded on a schedule with a relatively high probability of a response producing an outcome, a random ratio (RR-5), judgments of control declined as rates of response-independent outcomes increased. However, when response-dependent outcomes were delivered with a relatively low probability (RR-15), increasing the rate of response-independent outcomes increased rates of response and judgments of control. Experiment 2 replicated this effect, but also noted a differential effect of response-independent outcome and response-independent sensory presentations on response rate and judgments of causal effectiveness. Ratings of the context in which the conditioning occurred suggested these were correlated with total outcome presentation, and that the role of context on response rate and judgments of control may be important to consider.
\end{abstract}

Keywords Judgment of control · Response rate ·

Response-independent outcomes · Context conditioning ·

Humans

Understanding the conditions impacting judgments of control is important across a range of areas: basic cognitive functioning (Allan, 1993; Cheng, 1997; Einhorn \& Hogarth, 1986; Nevin \& Grace, 2000), applications in psychopathologies (Alloy \& Abramson, 1979; Blanco, Matute, \& Vadillo,

Phil Reed

p.reed@swansea.ac.uk

1 Department of Psychology, Swansea University, Singleton Park, Swansea SA2 8PP, UK
2012), development of therapies (Dimidjian, Barrera, Martell, Muñoz, \& Lewinsohn, 2011; Koller \& Kaplan, 1978), as well as in social (Crocker, 1981) and economic (Fenton-O'Creevy, Nicholson, Soane, \& Willman, 2003; Reed, 1999) psychology. The circumstances under which the causal structure of the environment can be understood are also thought to be important across species (Alloy \& Tabachnik, 1984; Wasserman, 1990). The latter suggestion has prompted a range of studies using procedures that are analogous to classical (Blanco, Matute, \& Vadillo, 2011; Miller \& Matute, 1996a) and instrumental (Reed, 1999, 2001a, b; Wasserman, Chatlosh, \& Neunaber, 1983) conditioning to explore the factors implicated in developing judgments of causation. Although these procedures do not employ "biologically" relevant stimuli (like food), they share procedural similarities with conditioning studies in which a response or stimuli is presented prior to an outcome.

The similarity of findings between causal reasoning and learning studies depends on a wide number of factors (Miller \& Matute, 1996b), including whether the task requires the individual to gain outcomes or assess the response-outcome relationships (Matute, 1996; Reed, 2001a). In fact, different processes operate when the outcome is hedonically or biologically neutral, as in most tasks of causal reasoning (Blanco et al., 2011), and when the outcome has some hedonic (Reed, 1994) or biological (Miller \& Matute, 1996b) significance. The current series of experiments focuses on exploring causal judgments in a task retaining significant components of an instrumental conditioning procedure - often termed a "naturalistic procedure" (Matute, 1996).

Most theories of human causal judgment can accommodate the finding that outcomes presented in the absence of an action typically decrease ratings of causal effectiveness (Allan, 1993; Cheng, 1997; Rescorla-Wagner, 1972). Although this effect has been noted in studies of causal judgment (Wasserman 
et al., 1983) and instrumental learning (Zeiler, 1968), some findings suggest an opposite effect can sometimes be obtained (Blanco et al., 2011; Koller \& Kaplan, 1978; Matute, 1996). For example, Matute (1996) studied causality judgments using a procedure in which participants worked for outcomes, and noted higher causal ratings when there were higher numbers of response-independent outcomes presented despite this finding being at odds with the straightforward interpretations of many theories of judgment. When individuals give high ratings of causal control in situations when their actions are not directly controlling the outcome, this can be termed "an illusion of control" (Langer, 1975), and this is of relevance to many situations, including those related to clinical (Alloy \& Abramson, 1979) and economic (Fenton-O'Creevy et al., 2003; Langer, 1975) settings.

Experimentally, the illusion of control effect appears to be found when the rate at which outcomes are delivered, and the rate at which responses are emitted, are high (Blanco, Matute, \& Vadillo, 2012; Rudski, 2004). A similar finding has also been observed in the nonhuman instrumental conditioning literature, and is often termed "superstitious conditioning." Although the presentation of response-independent reinforcers typically depresses responding (Burgess \& Wearden, 1986), presenting response-independent reinforcement can sometimes result in higher rates of instrumental responding (Lattal \& Bryan, 1976; Rudski, Lischner, \& Albert, 1999; Skinner, 1948). This is particularly noted when rates of response-dependent reinforcement are low (Lattal \& Bryan, 1976). Similarly, in the associative conditioning literature, potentiation rather than overshadowing of learning about a target by another cue, when the target-outcome relationship is weak, has been found (Clarke, Westbrook, \& Irwin, 1979; Schachtman, Reed, \& Hall, 1987).

Thus, there are multiple demonstrations that responseindependent outcomes can sometimes facilitate human causal judgments and also rates of instrumental conditioning in nonhumans (Blanco et al., 2012; Lattal \& Bryan, 1976). If this type of effect were noted using human participants in a "naturalistic" judgment paradigm (i.e., one in which outcomes had some value, see Matute, 1996), it is unclear how it could easily be accommodated into many theories of judgments of control that assume competition between the target response and the context as sources of prediction for the outcome (Allan, 1993; Cheng, 1997). However, one possible explanation of this effect is derived from the conditioning literature, and concerns the impact of response-independent reinforcement on motivation (Dickinson \& Dawson, 1988; Holmes, Marchand, \& Coutureau, 2010; Nevin \& Grace, 2000). Here it can be assumed that such response-independent outcomes may drive responding through increasing the motivational value of the context (Nevin \& Grace, 2000). This effect is often referred to as "Pavlovian-to-instrumental" transfer (Holmes et al., 2010; Rescorla \& Solomon, 1967), and it is suggested that incentive motivation conditioned to the Pavlovian CS energizes instrumental responding (Holland \& Gallagher, 2003). In the current context, Pavlovian conditioned incentive motivation may accrue to the context and, subsequently, may energize instrumental responding performed in that context (Nevin \& Grace, 2000). For example, pigeons respond at a low rate when response-independent reinforcement is superimposed over a schedule of responsedependent reinforcement, but, when placed in extinction, responding continues proportionally to the combined rate of response-dependent and independent reinforcement previously obtained in that context (Nevin \& Grace, 2000). However, such an effect has not been noted for humans.

This suggestion implies that response-independent outcomes, under some conditions, might maintain motivation to respond, and this would explain why response rates sometimes increase with response-independent outcomes (see Lattal and Bryan, 1976). In terms of judgments of causality, if the response-independent outcomes maintained responding in the above manner, this may give rise to spurious coincidences between their responses and outcomes, that are actually unrelated to those responses, but happen to take place close in time. This would tend to increase ratings of causal effectiveness that are given in that context. This account of an illusion of control is similar to the one offered by Blanco et al. (2011). This explanation may only hold for contexts that were not already relatively highly conditioned - i.e., those in which reinforcement already occurred at a reasonably high rate.

The current experiments explored the impact of responseindependent outcome delivery across a range of different response-dependent conditions in a naturalistic judgment task, and investigated the extent to which this impacts on rates of response, judgments of control, and the motivation to continue responding in the same context. Should similar findings to those discussed above be obtained, they would prove difficult for many theories of judgments of control, although they would be consistent with the operation of Pavolvian-toinstrumental transfer in these situations.

\section{Experiment 1}

A causal judgment task retaining aspects of an instrumental conditioning procedure, and which has previously been used to show similarities between response rates and causal judgments, was employed (Reed, 1999; see also Fenton-O'Creevy et al., 2003). The task involved making "investments" that involved some "cost" (the response) in order to maximize "returns" (the outcome), in a number of different "countries" (the contexts). Participants received exposure to high- or lowprobabilities of response-dependent outcomes, and to different rates of response-independent outcomes. If previous findings 
are to be extended to causal judgments, then, in the absence of response-independent outcomes, rates of response and judgments of causality should be higher with a higher-probability of a response-dependent outcome (Allan, 1993; Reed, 1999). For the high-probability response-dependent groups, response-independent outcomes should decrease responding (Allan, 1993), although, if response rates are high, then an illusion of control might be seen in the higher-rate responseindependent condition (Blanco et al., 2012). In contrast, for the low-probability response-dependence group, responseindependent outcome might serve to boost response rates (Lattal and Bryan, 1976). Participants were also asked to rate their motivation to return to the "country" to invest again, and this rating should increase as the total rate of outcomes (irrespective of their source) increases (Nevin and Grace, 2000). The above findings would be predicted by the operation of Pavlovian-to-instrumental transfer, but not by most theories of causal judgment.

\section{Method}

\section{Participants}

Forty-eight participants ( 27 female and 21 male), with a mean age of $21.65( \pm 3.06$; range $18-36)$ years, were recruited. This sample size was selected on the basis of previous research in the area. All were volunteers, and none was paid for their participation. Ethical approval was obtained from the Department of Psychology Ethics Committee.

\section{Apparatus}

The experiment was conducted on a BBC computer which controlled events displayed on the screen $(24 \mathrm{~cm} \times 17 \mathrm{~cm})$. Instructions were presented on the computer screen, and participants responded via the keyboard.

\section{Procedure}

Participants were tested individually in a small experimental room. Participants were presented with the following instructions via a screen:

"You have been given the job of testing the economies of a number of different countries. You must test how well your investments do, and report to the company that has hired you." Press the RETURN key to continue. "You can make an investment by pressing the SPACE $B A R$ of the computer. Each press will subtract money from your investment-fund. You may, or may not, receive income from the investment. Should you receive income, $£ 1,000$ will be added to your fund. You are free to make an investment at any time." Press the RETURN key to continue.

"After a period of time, you will be asked to report to the board on your activities. They will want to see a good return on your investment. They will also want you to give an estimate concerning a number of aspects of the time that you spent investing in that country. You will be required to give a rating on a scale of ZERO to 100 on aspects of the economy. Zero is always used to indicate a low rating on that aspect, and 100 is always used to indicate a high rating on that aspect." Press the RETURN key to continue.

"You will be involved in testing a number of different countries. Due to the nature of the economies of the various countries, it is to your advantage to invest some of the time, and not to invest some of the time." Press the RETURN key to start.

Participants in each of the two groups were then each exposed to the three conditions. The relationship between an investment (response) and a return (outcome) differed between the two groups. Both groups received response-dependent outcomes on a random ratio (RR) schedule; an RR-5 (i.e., each response had a .20 probability of producing an outcome), or an RR-15 schedule (i.e., each response had a .066 probability of an outcome). When an outcome was delivered, $£ 1,000$ was added to the investment-fund displayed in the middle of the screen, and the words "Successful Investment" were presented above the investment-fund running total for $1 \mathrm{~s}$. The investment-fund started at $£ 20,000$ for each condition.

Each group was exposed to the same three conditions ("countries"), presented in one of six counterbalanced orders. Each condition was clearly labelled: "Country 1, " "Country 2," or "Country 3," which appeared on the bottom of the screen during the condition. These conditions differed in the level of response-independent outcomes: none - no response-independent outcomes; lean response-independent outcomes delivered on a variable time (VT) 60-s schedule; and rich - responseindependent outcomes delivered on a VT 20-s schedule. When these response-independent outcomes were delivered, $£ 1,000$ was added to the investment-fund, and the words "Government Subsidy" appeared just above the investment-fund total.

Each condition lasted for $10 \mathrm{~min}$, following which the screen would clear, and the participants would be asked the following two questions (in a random order across participants and across conditions).

"How effective on a scale of 0 to 100 was an investment in this country?" Type your judgment. 
The participant then typed their judgment using the keyboard, and the screen cleared and the following question was asked:

\section{"How much on a scale of 0 to 100 would you like to return to this country to continue investing?" Type your judgment.}

The question regarding the effectiveness of the response was that used previously in studies of the impact of this procedure on such judgments (e.g., Reed, 1999). The second question aimed to assess the degree to which the context became valued, and was developed after testing the questions on ten participants (not included in the experiment) regarding what they thought the question assessed.

\section{Results and discussion}

Figure 1 displays the mean responses per minute for the two groups, for each of the three response-independent outcome conditions. Response rates for the RR-5 group were generally higher than those for the RR-15 group. This difference diminished as the probability of response-independent outcomes increased; manifest in an increase in response rate for the RR-15 group as the VT schedule became richer.

A two-factor mixed-model analysis of variance (ANOVA), with group (RR-5 versus RR-15) as a between-subject factor, and VT condition (none $\times$ VT-60 $\times$ VT-20), was conducted on these data. This analysis revealed a statistically significant main effect of group, $F(1,46)=8.55, p<.005$, partial eta $^{2}=$ .157 , no main effect of VT condition, $F(2,92)=1.39, p>.25$, partial eta ${ }^{2}=.029$, but a statistically significant interaction between the two factors, $F(2,92)=8.19, p<.001$, partial eta ${ }^{2}=.151$. Simple effects conducted for group at each level of VT condition revealed a statistically significant simple effect of group with no VT schedule, $F(1,92)=29.82, p<.001$, partial eta ${ }^{2}=.345$, a significant but smaller effect with VT-60, $F(1,92)=4.94, p<.05$, partial eta ${ }^{2}=.092$, but no difference between the RR groups with a VT-20 schedule, $F(1,92)=$ $0.06, p>.80$, partial eta ${ }^{2}=.001$. Simple effect analyses conducted between each condition for the groups, separately, revealed a statistically significant difference across VT condition for the RR-15 group, $F(2,92)=7.97, \mathrm{p}<.001$, = partial eta $^{2}=.298$, but not for the RR-5 group, $F(2,92)=1.62, \mathrm{p}>$ $.30,=$ partial eta ${ }^{2}=.056$.

Figure 2 displays the mean judgments of causal effectiveness (left panel) and motivation to revisit the country (right panel). Judgments (left panel) were generally higher for the RR-5 compared to the RR-15 group. This difference decreased as the VT schedule became richer, with a reduction in judgment for the RR-5 group, and an increase in judgment for the RR-15 group, as the VT schedule became richer.
A two-factor mixed-model ANOVA (group $\times$ VT condition) was conducted on these data and revealed a statistically significant main effect of group, $F(1,46)=91.35, p<.001$, partial eta ${ }^{2}=.665$, no main effect of VT condition, $F(2,92)=$ $1.07, p>.30$, partial eta ${ }^{2}=.023$, but a statistically significant interaction between the two factors, $F(2,92)=43.23, p<.001$, partial eta ${ }^{2}=.484$. Simple effects conducted for group at each level of VT condition revealed a statistically significant simple effect of group with no VT schedule, $F(1,92)=222.07, p<$ .001 , partial eta ${ }^{2}=.799$, and with VT-60, $F(1,92)=48.82, p<$ .001 , partial eta $^{2}=.394$, but no difference between the RR groups with a VT-20 schedule, $F(1,92)=3.50, p>.10$, partial $e t a^{2}=.055$. Simple effect analyses conducted between each condition for the groups, separately, revealed a statistically significant increasing linear trend for the RR-15 group, $F(1$, $92)=56.63, \mathrm{p}<.001,=$ partial eta $^{2}=.768$, and a significant decreasing linear trend for the RR-5 group, $F(1,92)=30.30$, $\mathrm{p}$ $<.001,=$ partial eta $^{2}=.530$.

Inspection of the data for motivation to revisit the country (Fig. 2, right panel) reveals a different pattern of data from response rates and judgments of causality. Motivation ratings were higher for the RR-5 group than for the RR-15 group. However, response-independent reinforcement tended to increase ratings for the RR-15, but not the RR-5, group. A twofactor mixed-model ANOVA (group $\times$ VT condition) conducted on these data revealed statistically significant main effects of group, $F(1,46)=103.29, p<.001$, partial eta $^{2}=$ .692 , and VT condition, $F(2,92)=27.48, p<.001$, partial eta $^{2}$ $=.374$, and a statistically significant interaction between the two factors, $F(2,92)=16.63, p<.001$, partial eta ${ }^{2}=.266$. Simple effects conducted for group at each level of VT condition revealed statistically significant simple effects of group with no VT schedule, $F(1,92)=174.20, p<.001$, partial eta ${ }^{2}$ $=.720$, and with VT-60, $F(1,92)=39.92, p<.001$, partial eta $^{2}$ $=.323$, and with a VT-20 schedule, $F(1,92)=35.40, p>.001$, partial eta ${ }^{2}=.489$. Simple effect analyses conducted between each condition for the groups, separately, revealed a statistically significant increasing linear trend for the RR-15 group, $F(1,92)=78.70, p<.001$, = partial eta ${ }^{2}=.870$, but no significant difference between the conditions for the RR-5 group, $F(1,92)=3.33, p>.05,=$ partial eta $^{2}=.099$.

Richer schedules of response-dependent outcomes generally produced higher rates of response and judgments causation than leaner schedules. However, this difference was reduced when response-independent outcomes were added reducing both rates and ratings on the rich schedule, but increasing rates and judgments on the lean schedule. These data partially replicate previous findings regarding the effect of increasing the rate of response-independent outcomes on judgments of control (Blanco et al., 2012; Matute, 1996), and replicate findings from the free-operant schedule literature showing response-independent reinforcement can sometimes increase rates of response (Lattal and Bryan, 1976). A novel 
Fig. 1 Results from Experiment 1. Mean rates of response for the two groups (receiving responsedependent reinforcement according to an RR-5 or RR015 schedule), in the three conditions: None $=$ no response-independent reinforcement; Lean = responseindependent reinforcement delivered on an FT-60-s schedule; Rich $=$ response-independent reinforcement delivered on an FT20 -s schedule. Error bars are $95 \%$ confidence limits

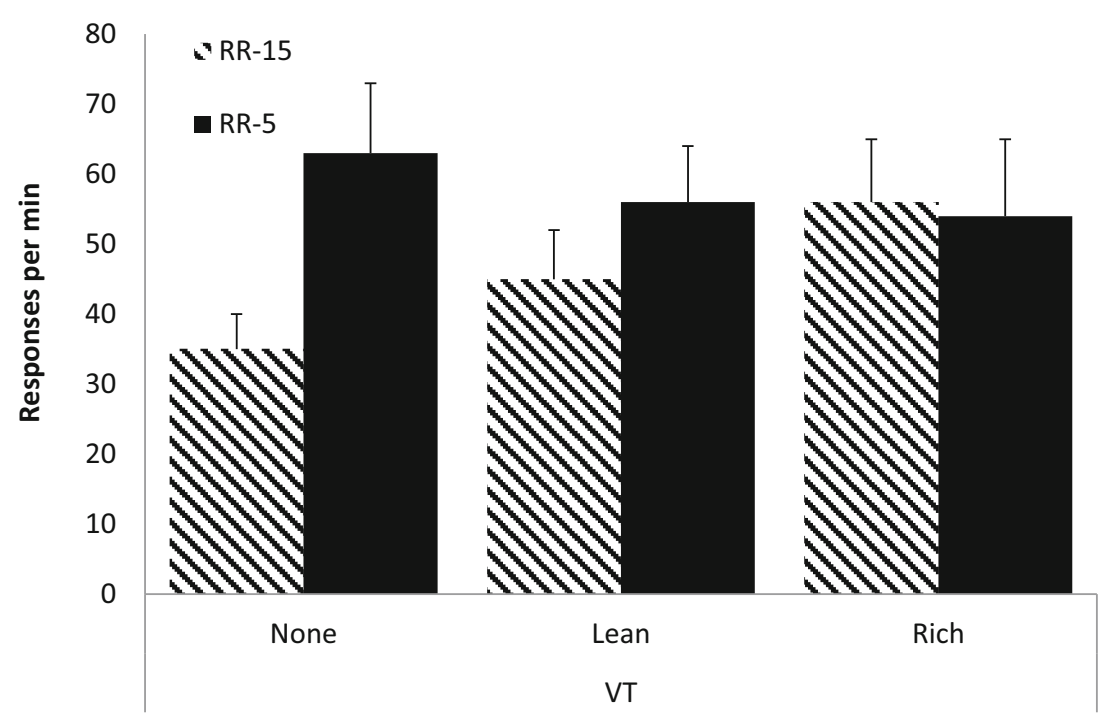

aspect of these results is their extension to a naturalistic judgment procedure in which rates of response and judgments are controlled in humans in a similar manner to that noted for nonhumans.

Table 1 shows the group mean outcomes per minute delivered for each group in all conditions, as well as the group mean rates at which scheduled response-dependent, all response-dependent (including chance pairings defined as outcomes delivered within $500 \mathrm{~ms}$ of a response), and response-independent outcomes (excluding programmed response-dependent outcomes occurring within $500 \mathrm{~ms}$ of a response). These data demonstrate that the RR-5 group earned more outcomes than the RR-15 group. There were different impacts of the addition of response-independent reinforcers across the two groups. For the RR-5 group, as the FT schedule became richer, there was a decrease in response-dependent reinforcement actually produced by responding. However, as many of the response-independent outcomes were emitted in close proximity $(500 \mathrm{~ms})$ to a response, this maintained the actual level of response-dependent outcomes experienced. Nevertheless, there was an increase in the number of response-independent reinforcers delivered in the rich (FT20) compared to the lean (FT-60) condition. In contrast, for the RR-15 group, the addition of increasing numbers of
Fig. 2 Results from Experiment 1. Mean rates of causal effectiveness and motivation for the two groups (receiving response-dependent reinforcement according to an RR-5 or RR015 schedule), in the three conditions: None $=$ no response-independent reinforcement; Lean = responseindependent reinforcement delivered on an FT-60-s schedule); Rich = responseindependent reinforcement delivered on an FT-20-s schedule). Error bars are $95 \%$ confidence limits

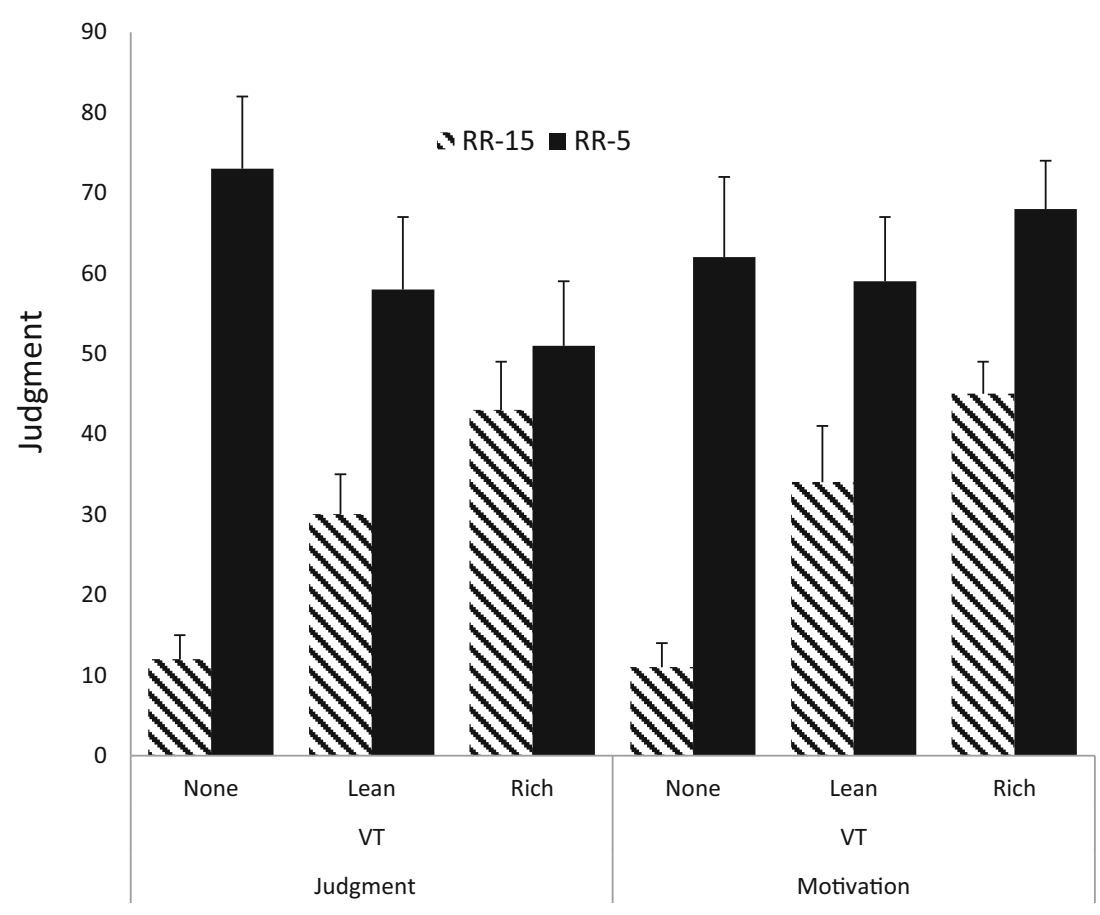


Table 1 Experiment 1. Group mean (standard deviation) outcomes per minute delivered for each group in all conditions, as well as the group mean rates at which scheduled response-dependent, all responsedependent (including chance pairings defined as outcomes delivered within $500 \mathrm{~ms}$ of a response), and response-independent outcomes (excluding programmed response-dependent outcomes occurring within $500 \mathrm{~ms}$ of a response)

\begin{tabular}{llllll}
\hline & & Outcomes & $\begin{array}{l}\text { Scheduled } \\
\text { dependent }\end{array}$ & $\begin{array}{l}\text { All } \\
\text { dependent }\end{array}$ & $\begin{array}{l}\text { Response } \\
\text { independent }\end{array}$ \\
\hline RR-5 & None & $12.75(4.99)$ & $12.75(4.99)$ & $12.75(4.99)$ & 0 \\
& Lean & $12.38(3.93)$ & $11.38(3.94)$ & $12.75(4.99)$ & $0.18(.22)$ \\
& Rich & $13.97(5.44)$ & $10.97(5.45)$ & $13.40(6.16)$ & $0.57(.71)$ \\
RR-15 & None & $2.36(.88)$ & $2.36(.88)$ & $2.36(.88)$ & 0 \\
& Lean & $4.03(1.15)$ & $3.03(1.15)$ & $3.72(1.38)$ & $3.08(2.41)$ \\
& Rich & $6.74(1.44)$ & $3.7491 .44)$ & $4.01(1.55)$ & $2.73(1.17)$ \\
\hline
\end{tabular}

response-independent reinforcement (i.e., FT-20 compared to FT-60) served to maintain numbers of response-dependent reinfocers obtained, and the number of reinforcers actually delivered in the absence of a response decreased.

Table 2 shows the correlations between all three outcome measures (response rate, judgment of causality, and judgment of motivation) and the number of outcomes presented, in terms of the total outcomes, response-dependent outcomes, and response-independent outcomes (excluding those that occurred with $500 \mathrm{~ms}$ of a response). These data are displayed

Table 2 Experiment 1. Correlations between all three outcome measures and the outcomes presented for the sample as a whole

\begin{tabular}{|c|c|c|c|}
\hline None & $\begin{array}{l}\text { Response } \\
\text { rate }\end{array}$ & $\begin{array}{l}\text { Causal } \\
\text { judgment }\end{array}$ & $\begin{array}{l}\text { Motivation } \\
\text { judgment }\end{array}$ \\
\hline Causal judgment & $.660 * * *$ & & \\
\hline Motivation & $.648 * * *$ & $.923 * * *$ & \\
\hline Total outcomes & $.918^{* * *}$ & $.841 * * *$ & $.827 * * *$ \\
\hline Response dependent & $.918 * * *$ & $.841 * * *$ & $.827 * * *$ \\
\hline Response independent & - & - & \\
\hline Lean & $\begin{array}{l}\text { Response } \\
\text { rate }\end{array}$ & $\begin{array}{l}\text { Causal } \\
\text { judgment }\end{array}$ & $\begin{array}{l}\text { Motivation } \\
\text { judgment }\end{array}$ \\
\hline Causal judgment & $.467 * * *$ & & \\
\hline Motivation & $.306^{* * *}$ & $.668^{* * *}$ & \\
\hline Total outcomes & $.737 * * *$ & $.710^{* * *}$ & $.625^{* * *}$ \\
\hline Response dependent & $.757 * * *$ & $.715^{* * *}$ & $.616^{* * *}$ \\
\hline Response independent & $-.927 * * *$ & $-.354^{*}$ & .201 \\
\hline Rich & $\begin{array}{l}\text { Response } \\
\text { rate }\end{array}$ & $\begin{array}{l}\text { Causal } \\
\text { judgment }\end{array}$ & $\begin{array}{l}\text { Motivation } \\
\text { judgment }\end{array}$ \\
\hline Causal judgment & $.443 * *$ & & \\
\hline Motivation & $.267^{*}$ & $.542 * * *$ & \\
\hline Total outcomes & $.654 * * *$ & $.525 * * *$ & $.671 * * *$ \\
\hline Response dependent & $.596^{* * *}$ & $.513 * * *$ & $.703 * * *$ \\
\hline Response independent & -.297 & $-.400 * *$ & $.765^{* * *}$ \\
\hline
\end{tabular}

for each of the three conditions across the entire sample. Inspection of these data reveals that, in all three conditions, the three outcome variables were significantly correlated with one another, although less strongly in the two conditions where there were response-independent reinforcements.

The relationship between response rate and outcomes, and between causal judgment and outcomes, were similar to one another. This correlation was positive with total outcomes, and also with response-dependent outcomes; but, when considering just the response-independent outcomes, this relationship was negative. Testing between the related correlation coefficients for response rate and outcome and judgment and outcome, for each of the three sources of outcome, revealed that in no case was the difference between the correlations between response rate and outcomes, and causal judgment and outcomes, significant, all $t \mathrm{~s}<1$.

In contrast, while the relationship between motivation judgment and the number of outcomes delivered was positive for total outcomes and response-dependent outcomes, and this correlation did not differ from that noted with response rate or causal judgment for either lean or rich conditions, all $t \mathrm{~s}<1$, the relationship between motivation judgment and responseindependent outcomes was positive for both the lean and the rich condition. There was a significant difference between the correlations with response-independent outcomes between motivation and response rate in the lean, $t(47)=10.82, p<$ .001 , and rich conditions, $t(47)=6.26, p<.01$, and also between the motivation judgment and causal judgment for the lean, $t(47)=3.91, p<.01$, and rich, $t(47)=6.43, p<.01$, conditions.

These results suggest that the effect of adding responseindependent reinforcement was dependent upon the degree to which response-independent reinforcement actually produced chance pairings with responses. To the extent that this occurred, rates of response and judgments of causal effectiveness increased. To the extent that there were outcomes presented that were not delivered in close temporal proximity to a response, response rates and causality judgments decreased. These findings are in line with most views of the impact of response-dependent and response-independent outcomes (see Allan, 1980).

However, this cannot be the full explanation of the results, as the impact of the scheduled response-independent outcomes was determined by the schedule of responsedependent outcomes in a manner that was not predictable from response rates alone. It has been suggested that higher rates of response would lead to more chance pairings of responses with scheduled outcomes that are not response-dependent, leading to an illusion of control (Blanco et al., 2011; 2012). If this were the case, and only the increase in chance pairings between responses and putative responseindependent outcomes was responsible for the findings, then the response-independent outcomes might have been 
expected to have a greater impact in the RR-5 condition which generated higher rats of response. This was not the case, suggesting an additional mechanism might mediate this effect.

In fact the present findings regarding the impact of the level of outcome delivery on the ratings given to the context are in line with findings from behavioral momentum studies (Nevin \& Grace, 2000). These results suggest that context conditioning (here measured by ratings of motivation to revisit the context/country) may be interacting with the probability of response-dependent outcomes to jointly determine response rates and causal judgments. This effect may potentially be mediated through the operation of Pavlovian-to-instrumental transfer (Rescorla \& Soloman, 1967). Increased context conditioning may elicit greater levels of responding in the RR-15 condition, leading to more responses and greater numbers of chance pairings between responses and outcomes scheduled to occur independently of responding. That this effect is most pronounced when response-outcome levels are weak fits with the literature on enhancement and potentiation of associations in classical conditioning (Clarke et al., 1979), and also with some findings regarding response-independent reinforcement in nonhumans (Lattal \& Bryan, 1976).

\section{Experiment 2}

Experiment 2 sought to explore a further effect noted in instrumental conditioning that might provide an explanation of the current findings. In addition to superstitious conditioning with biologically significant outcomes, a similar illusion of control finding has been noted with informational stimuli often termed "sensory superstition" (Morse \& Skinner, 1957). That is, a rating of causal effectiveness is given to a target when it is followed by any stimulus, irrespective of whether it is the outcome of interest or not. Indeed, Osborne and Shelby (1975) have suggested changes in sensory presentations in the environments can motivate responding, which might suggest that any additional stimulus change, if delivered at a sufficiently high rate, might serve to increase levels of context conditioning. In the response-independent conditions, the rate of stimulus presentation may have impacted on the ratings through this mechanism - an explanation which may also apply to the previous findings of Matute (1996; Blanco et al., 2011; 2012).

The literature regarding Pavlovian-to-instrumental transfer is mixed with respect to whether the response-independent outcome needs to be of the same type as the responsedependent outcome to produce the motivating effect of responding (see Holmes et al., 2010, for a review). The current experiment sought to test this with respect to such "naturalistic procedures" in judgment of control tasks. If the responseindependent outcome did not have to be similar to the response-dependent outcome, then a similar sensory- reinforcement induced effect might be seen, which could accommodate the results from Experiment 1 without recourse to incentive motivation effects. However, if the effect works through the conditioning of motivation to the context, then an illusion of control should only be observed in the condition with a response-independent outcome similar to the one produced by responding.

\section{Method}

Twenty-four participants (14 female and ten male), with a mean age of $21.08( \pm 2.60$; range $18-28)$ years, were recruited. All were volunteers, and none was paid for their participation. The apparatus was as described in Experiment 1.

All participants responded on an RR-15 schedule of response-dependent outcome presentation, and experienced three conditions (in one of six counterbalanced orders). In one condition (none), participants received no responseindependent outcomes or stimulation. In a second condition (financial), participants received response-independent outcomes on a VT-20-s schedule. In a final condition (information), participants received no financial response-independent outcomes, but informational stimuli on a VT-20-s schedule. These informational stimuli related to the economic situation in the hypothetical country (i.e., "Inflation is Stable"), and were presented just above the investment-fund. All other details of the experiment were as described in Experiment 1.

\section{Results and discussion}

Figure 3 displays the mean responses per minute for the three conditions. Response rates for the financial responseindependent outcomes were higher than those for the other two conditions. A repeated-measures ANOVA conducted on these data revealed a statistically significant main effect of condition, $F(2,46)=5.12, p<.01$, partial eta ${ }^{2}=.182$. Paired t-tests revealed the Financial condition had a higher response rate than the None, $t(23)=3.04, p<.005$, and Information, $t(23)=2.01,0.06>p>.05$, conditions. The None and Informational conditions did not differ from one another, $t(23)=1.42, p>.10$.

Figure 4 displays the mean judgments of causal effectiveness (left panel), and motivation to revisit the country (right panel). Judgments and motivation were higher in the Financial condition than in the other two conditions. A repeatedmeasures ANOVA conducted on the causal judgment data revealed a statistically significant main effect of condition, $F(2,46)=20.74, p<.001$, partial eta ${ }^{2}=.474$. Paired t-tests revealed the Financial condition had a higher judgment of causal effectiveness than the None, $t(23)=6.31, p<.001$, and the Information, $t(23)=5.72, p<.05$, conditions. The None and Informational conditions did not differ from one another, $t(23)=0.06, p>.90$. A repeated-measures ANOVA 
Fig. 3 Results from Experiment 2. Mean rates of response in the three conditions: None $=$ no response-independent reinforcement; Finance $=$ money response-independently delivered on an FT-20-s schedule;

Information $=$ information response-independently delivered on an FT-20-s schedule. Error bars are $95 \%$ confidence limits

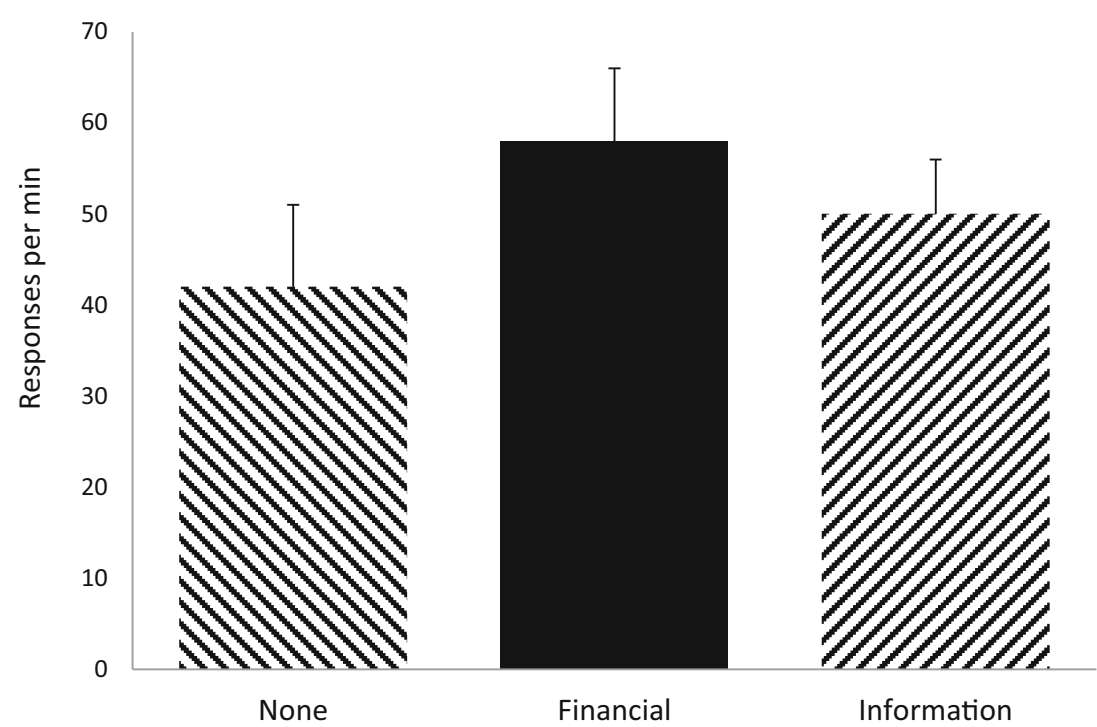

conducted on the motivation ratings revealed a statistically significant main effect of condition, $F(2,46)=39.29, p<$ .001 , partial eta ${ }^{2}=.631$. Paired t-tests revealed the Financial condition had a higher response rate than the None, $t(23)=$ $10.69, p<.001$, and the Information, $t(23)=7.03, p<.001$, conditions. The None and Informational conditions did not differ from one another, $t(23)=0.01, p>.90$.

These data replicated the effect of response-independent financial outcomes on a relatively lean (RR-15) schedule of response-dependent outcomes seen in Experiment 1. However, superimposing information relevant to the task had no such impact on rates of response, or judgments of causal effectiveness or motivation. This suggests that the response-independent outcomes did not impact ratings of the context through sensory superstition (Morse and Skinner, 1957), and that the effect of response-independent reinforcement is limited to situations in which this outcome is of the same type as the response-dependent reinforcement (Holmes et al., 2010).

Table 3 shows the group mean outcomes per minute delivered in all conditions, as well as the group mean rates at which scheduled response-dependent, all response-dependent (including chance pairings defined as outcomes delivered within $500 \mathrm{~ms}$ of a response), and response-independent outcomes (excluding programmed response-dependent outcomes occurring within $500 \mathrm{~ms}$ of a response). As in Experiment 1, many of the programmed response-independent reinforcers were delivered within $500 \mathrm{~ms}$ of a response, and served to increase the level of response-dependent reinforcement obtained. Table 3 also shows the rate at which financial and informational outcomes were delivered for the Information condition. The former rates were similar to those seen in the None condition, and the rates of all outcomes (combining both financial and informational) were similar to those noted in the Finance condition.
Fig. 4 Results from Experiment 2. Mean rates of causal effectiveness and motivation in the three conditions: None $=$ no response-independent reinforcement; Finance $=$ money response-independently delivered on an FT-20-s schedule; Information $=$ information response-independently delivered on an FT-20-s schedule. Error bars are $95 \%$ confidence limits

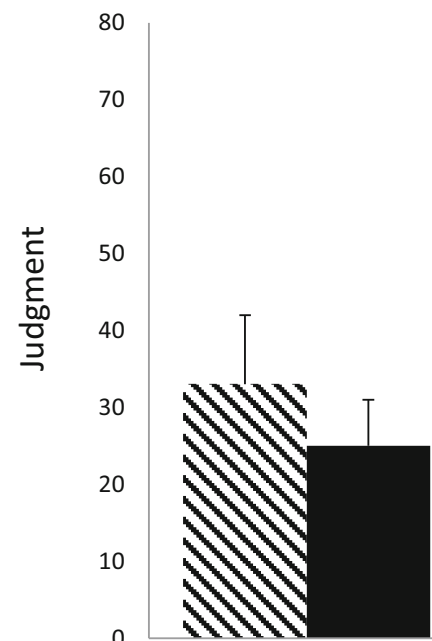

None

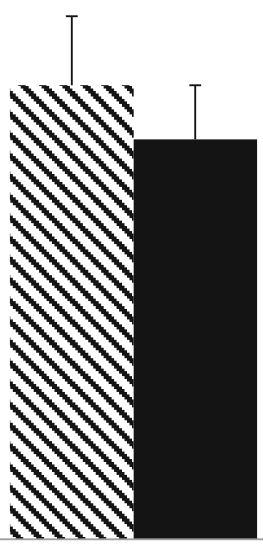

Financial
Judgment

- Motivation 
Table 3 Experiment 2. Mean outcomes (standard deviation) per minute delivered in all conditions, as well as the mean rates at which scheduled response-dependent, all response-dependent (including chance pairings defined as outcomes delivered within $500 \mathrm{~ms}$ of a response), and response-independent outcomes (excluding programmed responsedependent outcomes occurring within $500 \mathrm{~ms}$ of a response)

\begin{tabular}{lllll}
\hline & Outcomes & $\begin{array}{l}\text { Scheduled } \\
\text { dependent }\end{array}$ & $\begin{array}{l}\text { All } \\
\text { dependent }\end{array}$ & $\begin{array}{l}\text { Response } \\
\text { independent }\end{array}$ \\
\hline None & $2.81(1.42)$ & $2.81(1.43)$ & $2.81(1.43)$ & 0 \\
Finance & $6.84(1.24)$ & $3.85(1.28)$ & $6.38(1.74)$ & $0.47(.51)$ \\
Information (all) & $6.33(1.04)$ & $3.33(1.05)$ & $5.65(1.59)$ & $0.68(.56)$ \\
Information (rein) & $3.33(1.05)$ & $3.33(1.05)$ & $3.33(1.05)$ & 0
\end{tabular}

Table 4 shows the correlations between all three outcome measures (response rate, judgment of causality, and judgment of motivation) and the number of financial outcomes presented, in terms of the total outcomes, response-dependent financial outcomes, and response-independent financial outcomes (excluding those that occurred with $500 \mathrm{~ms}$ of a response). Inspection of these data reveals that, in all three conditions, the three outcome variables were significantly correlated with one another.

The relationship between response rate and outcomes, and between causal judgment and outcomes, were both positive with all outcomes, and with response-dependent outcomes. In contrast these relationships were negative for the response-

Table 4 Experiment 2. Correlations between all three outcome measures and the outcomes presented

\begin{tabular}{llll}
\hline None & $\begin{array}{l}\text { Response } \\
\text { rate }\end{array}$ & $\begin{array}{l}\text { Causal } \\
\text { judgment }\end{array}$ & $\begin{array}{l}\text { Motivation } \\
\text { judgment }\end{array}$ \\
\hline Causal judgment & $.493^{* *}$ & & \\
Motivation & $.349^{*}$ & $.490^{* *}$ & \\
Total outcomes & $.998^{* * *}$ & $.493^{* *}$ & $.349^{*}$ \\
Response dependent & $.998^{* * *}$ & $.493^{* *}$ & $.349^{*}$ \\
Response independent & - & - & - \\
Finance & Response & Causal & Motivation \\
& rate & judgment & judgment \\
Causal judgment & $.657^{* * *}$ & & \\
Motivation & $.763 * * *$ & $.642^{* * *}$ & \\
Total outcomes & $.998^{* * *}$ & $.657^{* * *}$ & $.763^{* * *}$ \\
Response dependent & $.998^{* * *}$ & $.630^{* * *}$ & $.734^{* * *}$ \\
Response independent & $-.836^{* * *}$ & $-.498^{*}$ & $.586^{* *}$ \\
Information & Response & Causal & Motivation \\
& rate & judgment & judgment \\
Causal judgment & $.670^{* * *}$ & & \\
Motivation & $.585^{* *}$ & $.701^{* * *}$ & \\
Total outcomes & $.999^{* * *}$ & $.670^{* * *}$ & $.585^{* * *}$ \\
Response dependent & $.994^{* * *}$ & $.648^{* * *}$ & $.581^{* *}$ \\
Response independent & $-.953^{* * *}$ & $-.587^{* *}$ & $.557^{* * *}$ \\
\hline
\end{tabular}

independent outcomes. Testing between the related correlation coefficients for response rate and outcome and judgment and outcome, for each of the three sources of outcome, revealed that in no case was the difference between the correlations between response rate and outcomes and causal judgment and outcome significant, all $t \mathrm{~s}<1$.

The relationship between motivation judgment and the number of outcomes delivered was positive for total outcomes and response-dependent outcomes, and this correlation did not differ from that noted with response rate or causal judgment for either lean or rich conditions, all ts $<1$. The relationship between motivation judgment and response-independent outcomes was positive for both the Finance and Information conditions. In the Financial condition, there was a significant difference between the correlations with response-independent outcomes between response rate and motivation judgment, $t(23)=4.87, p<.05$, and causal judgment and motivation judgment, $t(23)=2.91, p<.05$. In the Information condition, there was a significant difference between the correlations with response-independent outcomes between response rate and motivation judgment, $t(23)=3.72, p<.05$, and causal judgment and motivation judgment, $t(23)=2.98, p<.05$.

\section{General discussion}

Most theories of human causal judgments predict some form of competition between the target and alternative predictors of outcome (the context). These views suggest that as one predictor increases in strength, the other should decrease. The current data are problematic in this regard, as they show this simple relationship does not always hold (Blanco et al., 2012). Although there are plenty of demonstrations that context conditioning can suppress learning (Dickinson \& Charnock, 1985; Reed \& Reilly, 1990), other findings suggest this is only the case when the target-outcome association is strong, and that additional cues present during conditioning can sometimes potentiate an otherwise weak target-outcome association (Clarke et al., 1979; Schachtman et al., 1987). These findings imply, for this procedure, alternative accounts of the factors impacting human judgments of causation should be considered, including Pavlovian-to-instrumental transfer (Rescorla \& Soloman, 1967).

As with judgments of causal effectiveness, responseindependent reinforcement typically depresses response rate (Lattal, 1974), but this effect does not always occur (Lattal \& Bryan, 1976). In the current studies, adding responseindependent reinforcement enhanced responding when background rates of dependent reinforcement were low. Although response-independent reinforcement often reduces rates of target responding by reinforcing alternative behaviors (Eldridge, Pear, Torgrud, \& Evers, 1988), there were very few competing behaviors available in the current procedure, meaning this 
attenuating effect would not be pronounced, and leaving the motivating effect of response-independent reinforcement on the context to be observed more readily.

This enhancement of responding can be taken as analogous to a "reinstatement" effect, where extinguished responding returns following delivery of response-independent reinforcement (Dimidjian et al., 2011; Frank \& Lattal, 1976). This effect is often attributed to the motivating impact of the context in which responding occurs (Nevin \& Grace, 2000). Consistent with this view, ratings of the context did vary with the level of reinforcement (both earned and free) associated with that context. Also consistent with this view is the finding that there were no effects of response-independent outcomes on the ratings of motivation of participants in the RR- 5 in Experiment 1. If motivation was at a ceiling in this group, due to the high rate of reinforcement, it would not be surprising that increasing response-independent outcomes failed to produce an increase in response-rates and judgments: any ability of this variable to improve motivation is already at ceiling.

Of course, there are some potential alternative explanations that deserve brief mention. For example, where no responseindependent outcomes are delivered, it might be easier to estimate the amount of control over the outcome, which is why large differences in judgments and response rates are observed. However, as the number of response-independent outcomes increases, this inference might become increasingly difficult. When this difficulty becomes maximal (i.e., in the "rich" conditions), participants are no longer able to give an accurate estimate of their degree of control and, consequently, give intermediate judgments. This is consistent with Cheng's (1997) theory that, as the probability of the outcome in the absence of the cause increases to a maximal level, inferences about the causal power of the response become less and less certain.

If the Pavlovian-to-instrumental transfer account of the impact of background conditioning were also to be applied to judgments of causal effectiveness, it would imply accounts of responding, such as behavioral momentum accounts (Nevin \& Grace, 2000), may have some utility in explaining human judgments of causal effectiveness, including the phenomenon of illusion of control.

Of course there are a number of issues that should be considered when interpreting these data. Given the difference between the effects of response-independent reinforcement in the RR-5 and RR-15 of Experiment 1, it would be worthwhile for further studies to address the effects of parametric variations in the values of the response dependent and the VT schedules. Moreover, the impact of the questions used to assess the degree to which the context was conditioned could also be examined further to assess the exact nature of what is being judged. However, it should be noted that this rating scale differed in terms of its relationship to the various forms of outcome presented in manners predicted by behavioral momentum - that is, motivation was directly related to outcomes irrespective of their source, which was not true for effectiveness judgments - which suggests that this question was assessing a different aspect of the contingency to the effectiveness question. In this regard it is worth pointing out that an important aspect of behavioral momentum theory is the relation between the "persistence-enhancing" effects of contextual stimuli, and the choice of such contexts. The current motivational judgment question appears to assess the latter, and this could be further explored.

In summary, the present results suggest that context conditioning may interact with the level of experienced responsedependent outcomes to determine response rates and causal judgments. Increased context conditioning may produce greater levels of responding, leading to more responses and greater numbers of chance pairings between responses and outcomes scheduled to occur independently of responding.

Acknowledgments Thanks are due to Lisa A. Osborne for her support and comments.

\section{References}

Allan, L. G. (1980). A note on measurement of contingency between two binary variables in judgment tasks. Bulletin of the Psychonomic Society, 15, 147-149.

Allan, L. G. (1993). Human contingency judgments: Rule based or associative? Psychological Bulletin, 114(3), 435.

Alloy, L. B., \& Abramson, L. Y. (1979). Judgment of contingency in depressed and nondepressed students: Sadder but wiser? Journal of Experimental Psychology: General, 108(4), 441.

Alloy, L. B., \& Tabachnik, N. (1984). Assessment of covariation by humans and animals: The joint influence of prior expectations and current situational information. Psychological Review, 91(1), 112.

Blanco, F., Matute, H., \& Vadillo, M. A. (2011). Making the uncontrollable seem controllable: The role of action in the illusion of control. The Quarterly Journal of Experimental Psychology, 64(7), 1290-1304.

Blanco, F., Matute, H. A., \& Vadillo, M. (2012). Mediating role of activity level in the depressive realism effect. PLoS ONE, 7(9), e46203. doi:10.1371/journal.pone.0046203

Burgess, I. S., \& Wearden, J. H. (1986). Superimposition of responseindependent reinforcment. Journal of the Experimental Analysis of Behavior, 45(1), 75-82.

Cheng, P. W. (1997). From covariation to causation: A causal power theory. Psychological Review, 104, 367-405.

Clarke, J. C., Westbrook, R. F., \& Irwin, J. (1979). Potentiation instead of overshadowing in the pigeon. Behavioral and Neural Biology, 25(1), 18-29.

Crocker, J. (1981). Judgment of covariation by social perceivers. Psychological Bulletin, 90(2), 272.

Dickinson, A., \& Charnock, D. J. (1985). Contingency effects with maintained instrumental reinforcement. The Quarterly Journal of Experimental Psychology, 37(4), 397-416.

Dickinson, A., \& Dawson, G. R. (1988). Motivational control of instrumental performance: The role of prior experience of the reinforcer. The Quarterly Journal of Experimental Psychology, 40(2), 113-134.

Dimidjian, S., Barrera, M., Jr., Martell, C., Muñoz, R. F., \& Lewinsohn, P. M. (2011). The origins and current status of behavioral activation treatments for depression. Annual Review of Clinical Psychology, 7, 1-38. 
Einhorn, H. J., \& Hogarth, R. M. (1986). Judging probable cause. Psychological Bulletin, 99(1), 3-19.

Eldridge, G. D., Pear, J. J., Torgrud, L. J., \& Evers, B. H. (1988). Effects of prior response contingent reinforcement on superstitious behavior. Animal Learning \& Behavior, 16(3), 277-284.

Fenton-O'Creevy, M., Nicholson, N., Soane, E., \& Willman, P. (2003). Trading on illusions: Unrealistic perceptions of control and trading performance. Journal of Occupational and Organizational Psychology, 76, 53-68.

Frank, J. G., \& Lattal, K. A. (1976). Antecedent reinforcement schedule training and operant response reinstatement in rats. Animal Learning and Behavior, 4, 374-378.

Holland, P. C., \& Gallagher, M. (2003). Double dissociation of the effects of lesions of basolateral and central amygdala on conditioned stimulus-potentiated feeding and Pavlovian-instrumental transfer. European Journal of Neuroscience, 17(8), 1680-1694.

Holmes, N. M., Marchand, A. R., \& Coutureau, E. (2010). Pavlovian to instrumental transfer: A neurobehavioural perspective. Neuroscience \& Biobehavioral Reviews, 34(8), 1277-1295.

Koller, P. S., \& Kaplan, R. M. (1978). A two-process theory of learned helplessness. Journal of Personality and Social Psychology, 36, $1177-1183$.

Langer, E. J. (1975). The illusion of control. Journal of Personality and Social Psychology, 32(2), 311-328.

Lattal, K. A. (1974). Combinations of response-reinforcer dependence and independence. Journal of the Experimental Analysis of Behavior, 22(2), 357-362.

Lattal, K. A., \& Bryan, A. J. (1976). Effects of concurrent responseindependent reinforcement on fixed-interval schedule performance. Journal of the Experimental Analysis of Behavior, 26(3), 495-504.

Matute, H. (1996). Illusion of control: Detecting response-outcome independence in analytic but not in naturalistic conditions. Psychological Science, 7(5), 289-293.

Miller, R. R., \& Matute, H. (1996a). Biological significance in forward and backward blocking: Resolution of a discrepancy between animal conditioning and human causal judgment. Journal of Experimental Psychology: General, 125(4), 370.

Miller, R. R., \& Matute, H. (1996b). Animal analogues of causal judgment. Psychology of Learning and Motivation, 34, 133-166.

Morse, W. H., \& Skinner, B. F. (1957). A second type of superstition in the pigeon. American Journal of Psychology, 70, 308-311.

Nevin, J. A., \& Grace, R. C. (2000). Behavioral momentum: Empirical, theoretical, and metaphorical issues. Behavioral and Brain Sciences, 23(01), 117-125.
Osborne, S. R., \& Shelby, M. (1975). Stimulus change as a factor in response maintenance with free food available. Journal of the Experimental Analysis of Behavior, 24, 17-21.

Reed, P. (1994). Influence of the cost of responding. Memory \& Cognition, 22(2), 243-248.

Reed, P. (1999). Effect of perceived cost on judgments regarding the efficacy of investment. Journal of Economic Psychology, 20(6), 657-676.

Reed, P. (2001a). Human response rates and causality judgments on schedules of reinforcement. Learning and Motivation, 32(3), 332348.

Reed, P. (2001b). Schedules of reinforcement as determinants of human causality judgments and response rates. Journal of Experimental Psychology: Animal Behavior Processes, 27(3), 187.

Reed, P., \& Reilly, S. (1990). Context extinction following conditioning with delayed reward enhances subsequent instrumental responding. Journal of Experimental Psychology: Animal Behavior Processes, 16(1), 48.

Rescorla, R. A., \& Solomon, R. L. (1967). Two-process learning theory: Relationships between Pavlovian conditioning and instrumental learning. Psychological Review, 74(3), 151.

Rescorla, R. A., \& Wagner, A. R. (1972). A theory of Pavlovian conditioning: Variations in the effectiveness of reinforcement and nonreinforcement. Classical Conditioning II: Current Research and Theory, 2, 64-99.

Rudski, J. (2004). The illusion of control, superstitious belief, and optimism. Current Psychology, 22(4), 306-315.

Rudski, J. M., Lischner, M. I., \& Albert, L. M. (1999). Superstitious rule generation is affected by probability and type of outcome. Psychological Record, 49, 245-260.

Schachtman, T. R., Reed, P., \& Hall, G. (1987). Attenuation and enhancement of instrumental responding by signals for reinforcement on a variable interval schedule. Journal of Experimental Psychology: Animal Behavior Processes, 13(3), 271.

Skinner, B. E. (1948). Superstition in the Pigeon. Journal of Experimental Psychology, 38, 168-172.

Wasserman, E. A. (1990). Detecting response-outcome relations: Toward an understanding of the causal texture of the environment. The Psychology of Learning and Motivation, 26, 27-82.

Wasserman, E. A., Chatlosh, D. L., \& Neunaber, D. J. (1983). Perception of causal relations in humans: Factors affecting judgments of response-outcome contingencies under free operant procedures. Learning and Motivation, 14(4), 406-432.

Zeiler, M. D. (1968). Fixed and variable schedules of responseindependent reinforcement. Journal of the Experimental Analysis of Behavior, 11(4), 405-414. 